\title{
Validation in London of a physical activity questionnaire for use in a study of postmenopausal osteopaenia
}

\author{
Suzi Suleiman, Michael Nelson
}

\begin{abstract}
Study objective-To determine the validity of a self administered physical activity questionnaire to be used as part of a screening device for postmenopausal osteopaenia (with additional questions on medical history and calcium intake).

Design-A questionnaire was posted to 86 perimenopausal women to enquire about weekly hours spent in non-sedentary activity at work, in the household, and during leisure hours. Subjects who returned the questionnaire were visited at home and asked to complete a four day activity diary and subsequently to undertake a submaximal estimate of $\mathrm{VO}_{2} \mathrm{MAX}$, carried out using a treadmill ergometer. They were interviewed to clarify questionnaire and diary entries. Questionnaire validity was assessed in comparison with the diary estimates of hours of activity and with $\mathrm{VO}_{2}$ MAX.
\end{abstract}

Participants-A total of 86 perimenopausal women aged $43-54$ years were randomly selected from a GP list in Hammersmith, London. Thirty five women $(41 \%)$ returned the questionnaire. They were visited at home, given the diary to complete, and invited to attend the physiology laboratory for $\mathrm{VO}_{2} \mathrm{MAX}$ measurements. Twenty six of the 35 (74\%) completed the study and were included in the final analysis.

Main results-Women spent an average of 51 hours per week in non-sedentary activities. Questionnaire and diary yielded similar results $(51.05$ versus $51.30 \mathrm{~h} / \mathrm{wk})$, and there was a good correlation between diary and questionnaire estimates of total weekly hours of non-sedentary activity $(r=$ $0.45, p<0.05$ ). Other significant correlations were for standing $(r=0.69, p<0.01)$, leisure activities $(r=0.66, p<0.01)$, and for light household activities $(r=0.42$, $\mathbf{p}<0.05$ ). Correlations were better for employed than non-employed subjects. In relation to the diary, the questionnaire correctly classified $60 \%$ into the top or bottom half of the distribution of activity. Sensitivity and specificity of the questionnaire were both equal to $61.5 \%$.

Conclusions-The questionnaire is useful for classifying subjects according to their level of activity, especially when administered in conjunction with an interview. The four day diary provided a useful reference measure and a focus for dis- cussing activity patterns during an interview related to the questionnaire responses.

( $(\mathcal{F}$ Epidemiol Community Health 1997;51:365-372)

The report on physical activity by the National Heart Forum emphasises the need for reliable measures of activity in the population. ${ }^{1}$ However, physical activity is difficult to measure accurately, especially in epidemiological studies involving large numbers of subjects. ${ }^{2}$

Physical activity has been identified as an important risk factor for osteoporosis and its fractures. There is a positive association between bone parameters and physical activity, ${ }^{3-6}$ and increased physical activity may be associated with a reduced risk of osteoporosis. ${ }^{7}$ Recent epidemiological studies have concluded that low physical activity is a risk factor for fractures of osteoporosis. ${ }^{89}$ The effect of regular habitual exercise on the risk of hip fracture is evident from differences in hip fracture rates between groups of individuals with different lifestyles or living in different parts of the same country. Lower hip fracture incidence was found in rural or mountainous communities in Yugoslavia, ${ }^{10}$ Norway, ${ }^{11}$ and Sweden. ${ }^{12}$ Law et al ${ }^{13}$ have summarised evidence which shows that the risk of hip fracture is reduced by about half, in both sexes, as a result of regular habitual exercise. This protective effect of physical activity is likely to be permanent, as the effect of occupation is still apparent in the years following retirement. ${ }^{14}$ The effect of exercise may not be localised only to the exercised limb, ${ }^{1516}$ even when only moderate exercise is undertaken. ${ }^{17}$ Moreover, habitual exercise, physical fitness, and muscle strength all correlate well with bone mass in relatively sedentary individuals in both sexes, leading to the conclusion that physical fitness is a major determinant of femoral neck and lumbar spine bone mineral density. ${ }^{18}$

In the studies listed above, activity has been defined in a variety of ways, ranging from measures of hours spent in leisure or occupational activities to measure of physical fitness such as $\mathrm{VO}_{2} \mathrm{MAX}$. But in relation to bone health, weight bearing and muscle pull activities are the types of exercise most likely to maintain or increase bone mass.

Physical activity is a complex behaviour of many interrelated dimensions that is difficult to measure without bias. More than 30 different techniques are available for assessing physical activity, classifiable into seven major categories: 
calorimetry, job classification, survey procedures, physiological markers, behavioural observation, mechanical and electronic monitors, and indirect dietary estimates. ${ }^{19}$ Each of those techniques measures only one aspect of the entire behaviour pattern (eg energy expenditure with calorimetry, frequency and pattern of activity with survey procedures, etc). Furthermore, some of these techniques relate more clearly to some health problems than others (eg energy expenditure with obesity, intensity of aerobic activity with cardiovascular competence, and weight bearing or muscle loading activity with osteoporosis). Despite the variations in technique, however, there is a generally described consistent inverse relation between increased level of physical activity and the risk of coronary heart disease, osteoporosis, and type II diabetes. ${ }^{20}$

There is no validated questionnaire designed to relate present physical activity of muscle loading to bone density specifically for perimenopausal and newly postmenopausal women. The report by Cauley et al ${ }^{21}$ shows relatively poor agreement between the five most commonly used measures of activity in a group of postmenopausal women. The measures included the Paffenbarger questionnaire ${ }^{22}$ (which focuses mainly on leisure time activities); a modification of the Paffenbarger questionnaire, which focuses only on sport activities; the Baeke questionnaire $^{23}$ (which uses Liekert scales to classify subjects according to work, leisure, and sport activities, but omits activities of daily living); a large scale integrated activity monitor; and an estimate of caloric intake based on three day food records. Excluding comparisons of subsets of activity estimates within any one method, the best correlations between measures were 0.48 (Baeke leisure time index versus Paffenbarger blocks walked per day), 0.36 (Baeke leisure time index versus Paffenbarger $\mathrm{kcal} / \mathrm{wk}$ ) and 0.26 (Baeke sport index versus Paffenbarger $\mathrm{kcal} / \mathrm{wk}$ ). All other correlations were less than 0.25 . None of these comparisons shows strong agreement between methods, and all of the measures relate to only a subset of weight bearing or muscle pull activities. Moreover, none of the methods is strongly focused on activities of daily living such as housework, which, among women especially, may account for a substantial amount of the variation in activity levels between subjects.

Pols et $a l,{ }^{24}$ using the Baeke questionnaire modified to include three additional questions on leisure activity, showed somewhat better agreement between the Baeke index and estimates of energy expenditure in 55 women $(r=0.44)$. These workers concluded, however, that their modification was not adequate to obtain good classification of activity levels of older women and that questionnaires designed for this group should include more emphasis on household tasks.

The study by Voorrips et $a l^{25}$ in 31 women aged 63-80 years showed good rank correlations between their questionnaire responses (which included a number of questions on activities of daily living) and repeat 24 hour recalls of activity $(r=0.78)$ and pedometer

\section{KEY POINTS}

- A quick and accurate method has been developed to assess the usual levels of physical activity which influence the rate of bone loss and subsequent risk of osteoporotic fracture.

- A questionnaire to assess physical activity was validated against a 4 day activity diary; the sensitivity and specificity of the questionnaire were $61.5 \%$.

- The women spent on average about 51 hours per week in non-sedentary activities at work, at home, and in leisure pursuits.

- A subsequent study has shown that women with below average activity levels have significantly lower bone mass.

readings $(r=0.73)$. However, the wide age range was associated with a much wider range of activity levels (including very sedentary subjects) than would commonly be encountered in perimenopausal and newly postmenopausal women, and the good agreement between questionnaire and recalls may be due in part to similarities in the methods of reporting activity.

This study aimed to test the validity of a self administered questionnaire that asks about occupational, household, and leisure time activities in terms of hours or minutes per week. The purpose was to estimate hours per week of total non-sedentary activity in a group of perimenopausal and newly postmenopausal women, for use as part of a screening device related to risks of osteopaenia (low bone mass). The ultimate aim was to be able to identify women in the bottom half of the distribution of physical activity. The questionnaire was validated against a four day diary of activity, elaborated in an interview, and an estimate of $\mathrm{VO}_{2}$ MAX using treadmill ergometry.

\section{Methods}

SAMPLE

Eighty six perimenopausal white women aged 45-54 years and living in west London, were randomly selected from a GP list in Hammersmith, London and sent an invitation to take part in the study and a copy of the activity questionnaire. Thirty five women responded by completing the questionnaire and were recruited into the study. Twenty nine of the 35 women completed the other parts of the study in September 1990. Three subjects did not fill in their diaries satisfactorily and were excluded, and 26 subjects were included in the final analysis.

QUESTIONNAIRE AND DIARY

The questionnaire (see Appendix I) was a shortened version of that described by Nelson et al, ${ }^{26}$ modified to emphasise the main activities related to bone health. It was sent by mail to each participant for completion at home. Questions covered the following: 
Table 1 Mean (SD) and range of values of the physical characteristics of the 26 women recruited in the validation study.

\begin{tabular}{lccl}
\hline Variable & Mean & $(S D)$ & Range \\
\hline Age $(\mathrm{y})$ & 48.8 & $(2.84)$ & $43-54$ \\
Height $(\mathrm{m})$ & 1.63 & $(0.05)$ & $1.53-1.71$ \\
Weight $(\mathrm{kg})$ & 65.0 & $(10.16)$ & $50-90$ \\
Body mass index $\left(\mathrm{kg} / \mathrm{m}^{2}\right)$ & 24.3 & $(3.87)$ & $19-33.4$ \\
\hline
\end{tabular}

- Occupational activities, including type of work, hours of work per week, hours spent sitting, standing, walking or other activities (eg bending) including the time spent during breaks, and time spent on journey to and from work (the round trip), including sitting, standing, walking, or cycling;

- Household activities at three levels (light, moderate, and heavy) and the number of hours spent weekly doing each type; and

- Leisure time activities, including sporting activities at four levels (light, moderate, hard, and very hard), for which respondents were asked to note the time spent per occasion on each activity listed, how many occasions per month, and how many months per year.

After two to four days, a visit was arranged at the subjects' homes, where the questionnaire responses were clarified and checked for completeness. The subjects were given a four day diary in which to keep a record of all their activities on two weekdays and two weekend days (see Appendix II). If they worked at the weekend, they were asked to consider these days as working days and their off-days during the week as weekend days. Each diary was divided into half hour intervals, and subjects were asked to record their activity every half hour by entering a letter to denote the type of activity (eg $S=$ sitting, $W=$ waking), and a brief one or two word description. At the end of the diary, questions were included about routine weekly activities done on specific days of the week and their type, duration, and intensity. An explanation about how to fill in the diary was given on the introductory page, and was repeated verbally. At the end of the home visit, each subject was given an appointment to attend the Physiology Department at King's College and to bring the completed diary. The diary was then checked at interview and the usual pattern of weekly leisure activity elu-

Table 2 Mean (SE), mean differences, and Pearson correlation coefficients of nonsedentary physical activity based on diaries and questionnaires of 26 women

\begin{tabular}{|c|c|c|c|c|c|c|c|}
\hline \multirow{2}{*}{$\begin{array}{l}\text { Non-sedentary } \\
\text { activity }(h)\end{array}$} & \multicolumn{2}{|l|}{ Diary } & \multicolumn{2}{|c|}{ Questionnaire } & \multicolumn{2}{|c|}{$D-Q$ difference } & \multirow[t]{2}{*}{$r$} \\
\hline & Mean & $(S E)$ & Mean & $(S E)$ & Mean & $(S E)$ & \\
\hline Standing & 3.74 & $(0.93)$ & 4.79 & $(1.44)$ & -1.04 & $(1.04)$ & $0.69 * *$ \\
\hline Walking & 13.47 & $(1.03)$ & $\begin{array}{c}12.7 \\
0.88\end{array}$ & $\begin{array}{l}(2.0) \\
(0.49)\end{array}$ & $\begin{array}{r}1.77 \\
-088\end{array}$ & $\begin{array}{l}(2.2) \\
(0.49)\end{array}$ & 0.06 \\
\hline Light household & 20.5 & $(1.18)$ & $\begin{array}{r}0.80 \\
17.31\end{array}$ & $\begin{array}{l}(0.49) \\
(2.09)\end{array}$ & $\begin{array}{r}-0.88 \\
3.19\end{array}$ & $\begin{array}{l}(0.49) \\
(1.93)\end{array}$ & $\overline{0.42 *}$ \\
\hline Moderate household & 6.76 & $(0.66)$ & 8.64 & (1.09) & -1.87 & (1.06) & 0.35 \\
\hline Heavy household & 0.37 & $(0.13)$ & 1.05 & $(0.29)$ & $-0.68^{*}$ & $(0.31)$ & 0.06 \\
\hline Light leisure & 0.0 & $(0.0)$ & 0.22 & $(0.18)$ & -0.22 & $(0.18)$ & 0.0 \\
\hline Moderate leisure & 5.40 & $(0.75)$ & 2.67 & $(0.59)$ & $2.73^{* * *}$ & 0.65 & $0.55^{* *}$ \\
\hline Hard leisure & 0.72 & $(0.25)$ & 0.68 & $(0.28)$ & 0.04 & $(0.23)$ & $0.63^{* *}$ \\
\hline Very hard leisure & 0.08 & $(0.05)$ & 0.17 & $(0.10)$ & -0.09 & $(0.62)$ & $0.82^{* *}$ \\
\hline Other work & 0.0 & $(0.0)$ & 2.19 & (1.38) & $-2.19^{* * *}$ & 1.38 & 0.0 \\
\hline Total & 51.05 & $(1.95)$ & 51.30 & (3.84) & -0.25 & (3.45) & $0.45^{*}$ \\
\hline Light & 24.24 & (1.25) & 22.32 & (2.24) & 1.9 & (2.15) & 0.35 \\
\hline Moderate-plus & 26.81 & (1.57) & 26.8 & (2.71) & 0.01 & (2.37) & $0.49^{*}$ \\
\hline
\end{tabular}

${ }^{*} \mathrm{p}<0.05,{ }^{* *} \mathrm{p}<0.01,{ }^{* * *} \mathrm{p}<0.001$ cidated, based on the responses to the questions in the end of the diary.

\section{MEASUREMENT OF $\mathrm{VO}_{2}$ MAX}

Weight (to the nearest $0.1 \mathrm{~kg}$ ) and height (to the nearest $0.1 \mathrm{~cm}$ ) were measured without jacket and shoes using Avery scales and a fixed stadiometer. Pulse and ECG were measured using a three electrode recording device and $\mathrm{VO}_{2}$ MAX was estimated using three measurements of work on a treadmill. Electrodes (3M Red Dot) were attached to the subject's chest and connected to a Roche 123-102 ECG monitor and Electromed MX216 recorder. The subjects stood on the treadmill (Morgan), a safety harness was fastened, and the positioning of the electrodes was checked. The treadmill was started at $0^{\circ}$ incline and the subject was asked to walk on the treadmill for 3 minutes at a speed of $3 \mathrm{~km} / \mathrm{h}$. After fitting a nose clip and breathing tube attached to a two way valve and Douglas bag, and allowing one minute for the subject to accustom herself to the apparatus, a one minute timed sample of respired air was collected in the Douglas bag while treadmill revolutions were being counted.

After removing the mouth piece and nose clips, the treadmill incline was increased to $2^{\circ}$ at the same speed, subjects were given $3 \mathrm{~min}$ utes to adjust to the new work load, and a respired air sample was collected as before. A third respired air sample was also collected at $4^{\circ}$ incline. After the three samples had been collected, the treadmill was stopped and the subject was seated until their heart rate had returned to normal. Measurements of oxygen and carbon dioxide content were made with a Servomex type OA250 oxygen analyser and digital carbon dioxide analyser (H\&BUras). Total volume of gas was measured using a Parkinson Cowan gas metre. $\mathrm{VO}_{2} \mathrm{MAX}$ was determined using the method of Astrand and Rodhal. ${ }^{27}$

\section{STATISTICAL ANALYSIS}

The mean (SD) was calculated for the different indices of physical activity reported in the questionnaires and diaries. Differences between diary and questionnaire estimates of activity were assessed by paired $t$ test. Pearson correlation coefficients were calculated to determine the strength of the relationship between estimates of physical activity using diaries and questionnaires. The validity of the questionnaire for correct classification of subjects into "high" or "low" (above or below the median) activity levels was expressed in terms of sensitivity and specificity. Agreement between diary and questionnaire according to classification of activity into "high" or "low" was assessed by Cohen's kappa. The study with a sample size of 26 had an $80 \%$ power to detect statistically significant correlation coefficients equal to 0.52 (significant at the 5\% level). Analyses were conducted using SPSS. ${ }^{28}$ 
Table 3 Mean (SE), mean differences, and Pearson correlation coefficients of nonsedentary physical activity based on diaries and questionnaires of 18 perimenopausal employed women.

\begin{tabular}{|c|c|c|c|c|c|c|c|}
\hline \multirow{2}{*}{$\begin{array}{l}\text { Non-sedentary } \\
\text { activity (h) }\end{array}$} & \multicolumn{2}{|l|}{ Diary } & \multicolumn{2}{|c|}{ Questionnaire } & \multicolumn{2}{|c|}{$D-Q$ difference } & \multirow[t]{2}{*}{$r$} \\
\hline & Mean & $(S E)$ & Mean & $(S E)$ & Mean & $(S E)$ & \\
\hline Standing & 5.41 & $(1.15)$ & 6.91 & (1.88) & -1.51 & $(1.51)$ & $0.6^{* *}$ \\
\hline Walking & 13.84 & $(1.22)$ & 14.2 & (2.67) & -0.36 & (3.0) & -0.06 \\
\hline Cycling & - & - & 1.08 & $(0.8)$ & -1.08 & $(0.8)$ & - \\
\hline Light household & 19.03 & $(1.31)$ & 15.31 & (2.47) & $3.73^{*}$ & 1.7 & $0.76^{* *}$ \\
\hline Moderate household & 6.79 & $(0.89)$ & 6.77 & (1.07) & 0.02 & (1.06) & 0.43 \\
\hline Heavy household & 0.32 & $(0.13)$ & 0.79 & $(0.33)$ & -0.48 & $(0.38)$ & -0.21 \\
\hline Light leisure & 0.00 & 0.00 & 0.05 & $(0.2)$ & -0.05 & $(0.2)$ & 0.0 \\
\hline Moderate leisure & 5.20 & $(0.81)$ & 2.34 & $(0.49)$ & $2.86^{* *}$ & $(0.83)$ & 0.25 \\
\hline Hard leisure & 0.39 & $(0.19)$ & 0.32 & $(0.13)$ & 0.07 & $(0.14)$ & $0.71^{* * *}$ \\
\hline Very hard leisure & 0.10 & $(0.07)$ & 0.22 & $(0.14)$ & -0.12 & $(0.09)$ & $0.85^{* *}$ \\
\hline Other work & - & - & 3.17 & (1.96) & -3.17 & (1.96) & - \\
\hline Total & 51.07 & $(2.49)$ & 51.16 & (4.94) & -0.09 & (4.16) & $0.54^{*}$ \\
\hline Light & 24.44 & (1.58) & 22.27 & (2.83) & 2.17 & $(2.09)$ & $0.69 * *$ \\
\hline Moderate-plus & 26.63 & $(1.76)$ & 25.73 & $(2.96)$ & 0.9 & $(2.99)$ & 0.28 \\
\hline
\end{tabular}

${ }^{*} \mathrm{p}<0.05,{ }^{* *} \mathrm{p}<0.01$

Table 4 Mean (SE), mean differences, and Pearson correlation coefficients of nonsedentary physical activity based on diaries and questionnaires of 8 non-employed women

\begin{tabular}{|c|c|c|c|c|c|c|c|}
\hline \multirow{2}{*}{$\begin{array}{l}\text { Non-sedentary activity } \\
\text { (h) }\end{array}$} & \multicolumn{2}{|l|}{ Diary } & \multicolumn{2}{|c|}{ Questionnaire } & \multicolumn{2}{|c|}{$D-Q$ difference } & \multirow[t]{2}{*}{$r$} \\
\hline & Mean & $(S E)$ & Mean & $(S E)$ & Mean & $(S E)$ & \\
\hline Standing & 0.0 & $(0.0)$ & 0.0 & $(0.0)$ & 0.0 & $(0.0)$ & 0.0 \\
\hline Walking & 12.62 & (2.0) & 9.31 & (2.36) & 3.31 & $(2.42)$ & 0.39 \\
\hline Cycling & - & - & 0.44 & $(0.26)$ & -0.44 & $(0.26)$ & - \\
\hline Light household & 23.81 & $(2.1)$ & 21.81 & (3.66) & 1.99 & $(5.21)$ & 0.61 \\
\hline Moderate household & 6.72 & $(0.86)$ & 12.85 & (1.99) & $-6.13^{*}$ & (1.79) & -0.43 \\
\hline Heavy household & 0.49 & $(0.33)$ & 1.63 & $(0.52)$ & -1.13 & $(0.51)$ & 0.36 \\
\hline Light leisure & 0.00 & $(0.0)$ & 0.62 & $(0.57)$ & -0.62 & $(0.57)$ & 0.0 \\
\hline Moderate leisure & 5.85 & (1.74) & 3.41 & (1.61) & 2.4 & (1.06) & $0.80^{* *}$ \\
\hline Hard leisure & 1.48 & $(0.62)$ & 1.5 & $(0.82)$ & -0.02 & $(0.71)$ & 0.54 \\
\hline Very hard leisure & 0.06 & $(0.06)$ & 0.06 & $(0.03)$ & 0.0 & $(0.04)$ & 0.63 \\
\hline Other work & - & - & - & - & - & - & - \\
\hline Total & 51.02 & (3.19) & 51.63 & $(6.15)$ & -0.60 & $(6.45)$ & 0.17 \\
\hline Light & 23.81 & (2.11) & 22.43 & (3.8) & 1.38 & (5.43) & -0.66 \\
\hline Moderate-plus & 27.21 & (3.43) & 29.2 & $(6.0)$ & -1.99 & (3.93) & $0.79 * *$ \\
\hline
\end{tabular}

${ }^{*} \mathrm{p}<0.05,{ }^{* *} \mathrm{p}<0.01$ $(p>0.05)$. There were statistically significant differences between the mean diary and questionnaire estimates of activity for "heavy household" $(0.37 \mathrm{~h}$ versus $1.05 \mathrm{~h})$, "moderate leisure" ( $5.4 \mathrm{~h}$ versus $2.67 \mathrm{~h}$ ), and "other work" $(0.0 \mathrm{~h}$ versus $2.19 \mathrm{~h})$ categories. Correlations between diary and questionnaire estimates of activity ranged from zero for "light leisure" and "other work" (there were no corresponding entries in the diaries), to 0.82 for "very hard leisure" (due to presence of zero values - only three subjects reported activity at this level). The correlation for "total activity" was 0.45 $(p<0.05)$. For activities such as "standing" and "light household" (which together accounted for almost half of daily activity) the correlation coefficients were $0.69 \quad(\mathrm{p}<0.01)$ and 0.42 $(\mathrm{p}<0.05)$, respectively.

Employed women (table 3 ) had statistically significant correlations between the diary and questionnaire responses for "standing" $(\mathrm{p}<0.01)$, "light household" ( $\mathrm{p}<0.01)$, "hard leisure" ( $p<0.01)$, "very hard leisure" $(p<0.01)$, "total activity" ( $p<0.05)$, and "light" $(p<0.01)$. The significant values for "hard leisure" and "very hard leisure" were again due to a large number of zero values. Statistically significant differences between the diary and questionnaire means were observed for "light household activity" $(\mathrm{p}<0.05)$, and for "moderate leisure" $(p<0.01)$. Non-employed women (table 4) had correlations between the diary and questionnaire responses which reached statistical significance only for "moderate leisure" and "moderate-plus" $(p<0.01)$, due in part to the small number of subjects. Significant differences were observed between the means of "moderate household activity" $(p<0.05)$. The correlations were generally better for the employed women than the non-employed women, especially for daily activities such as "standing" and "light household" and for the "total".

Figure 1 shows questionnaire versus diary estimates of total hours of non-sedentary activity per week for 26 perimenopausal women. The regression line $(Y=0.9 x+5.6)$ between the two measures has a slope not significantly different from 1.0.

Table 5 shows the classification between the questionnaire and diary responses above and below 50 hours (median) total non-sedentary activity per week. The sensitivity and the specificity were both $61.5 \%$, and Cohen's kappa $=$ 0.23 .

There were no statistically significant correlations between $\mathrm{VO}_{2} \mathrm{MAX}$ and the total hours of non-sedentary activity estimated either from the diary or the questionnaire, nor for any single categories of activity, with the exception of heavy household activities based on the diary (but for which only six women had non-zero values). other than standing and walking (eg bending, carrying or moving objects); "Light" is the sum of standing and light household and leisure activities; and "Moderate-plus" is the sum of moderate and heavy household activities, walking, cycling, and moderate, hard, and very hard leisure activities.

Table 2 shows that mean total hours of activity were similar for diary and questionnaire

\section{Discussion}

Although only 35 of the 86 subjects who were approached responded to the initial letter, many subjects had either moved or were away on holiday during the period of the study (July- $c$ 


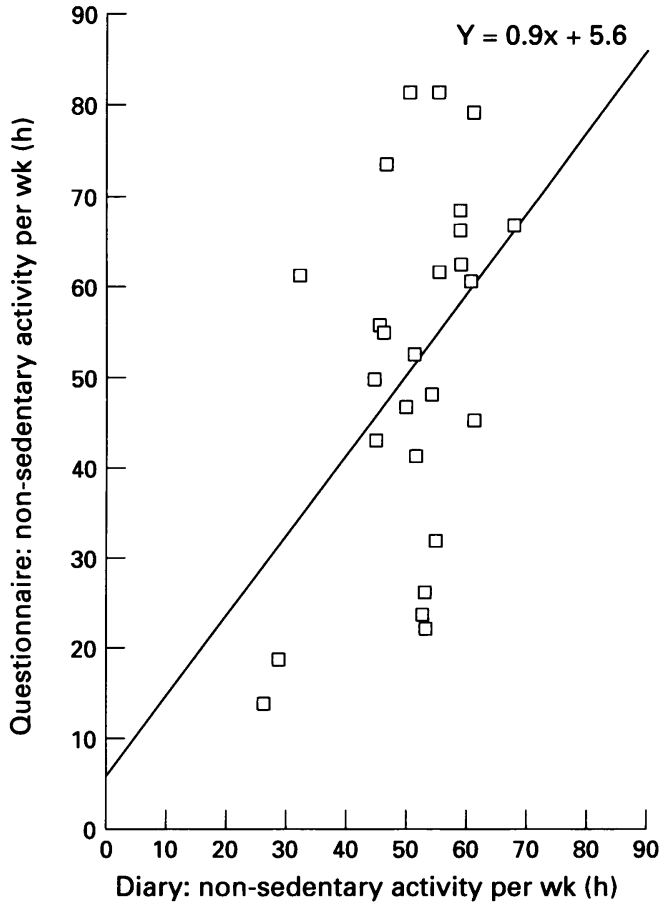

Figure 1 Questionnaire versus diary estimate of total hours of non-sedentary activity per week $(n=26)$.

Table 5 Agreement of classification of subjects between the diary and the questionnaire according to activity greater than or less than 50 hours per week

\begin{tabular}{llll}
\hline Diary & \multicolumn{2}{l}{ Questionnaire } & Total \\
\cline { 2 - 3 } & $<50 \mathrm{~h} / \mathrm{wk}$ & $\geq 50 \mathrm{~h} / \mathrm{wk}$ & \\
\hline$<50 \mathrm{~h} / \mathrm{wk}$ & 8 & 5 & 13 \\
$\geq 50 \mathrm{~h} / \mathrm{wk}$ & 5 & 8 & 13 \\
Total & 13 & 13 & 26 \\
\hline
\end{tabular}

September). Time constraints meant that only three attempts were made within a two week period to contact each subject. Of the 35 recruited, six subjects failed to complete the treadmill test, and a further three had incomplete diaries. The age and body size characteristics of the 26 women who completed the study (table 1) are similar to those for women in this age range reported in the dietary and nutritional survey of British adults, ${ }^{29}$ and lead us to believe that for the purposes of the validation study, the group was likely to be representative of perimenopausal women living in the west London area.

Table 2 shows that for the average total numbers of hours spent in non-sedentary activities there was good agreement between diary and questionnaire, although for individual categories of activity agreement was not so close. There were statistically significant differences for "heavy household", "moderate leisure" and "other work" (paired $t$ test). The slight overestimation of "heavy household" activity in the questionnaire may be related to the attitudes of the women towards heavy activities. They are more tiring than light activities, which were generally under-reported in the questionnaire. Due to the infrequent nature of heavy activities, women may have felt more aware of the time spent engaged in these activities and tended therefore to overestimate in their questionnaire responses. The same comments apply to a lesser extent to moderate household activities. Conversely, the under-reporting of light activities in relation to the diary, although not statistically significant, may be due to their more inconsequential nature and the difficulty of making a mental tally of the total time devoted to activities which occur many times throughout the day.

Moderate leisure activities were under reported by $50 \%$ in the questionnaire. The season of administration of the validation study (JulySeptember) might have influenced this estimation. Subjects reported being more active in their leisure time in summer than at other times of the year, so more hours were reported in the diaries. The questionnaire, on the other hand, reflected the time devoted to such activities over the whole year. The correlation $(r=0.49)$ between questionnaire and diary for "moderate-plus", which included over half of the hours of non-sedentary activity (including most of the leisure time activities), reflected generally good agreement between the two measures.

Subjects complained about the design of the questions for household activities being divided into three levels. After reviewing the questionnaires, subjects were often found to have allocated more hours to the three separate categories than they reported spending in total, which they found easier to estimate. Light and moderate household activities especially tended to be initially over estimated. Following discussion, light household activities were more likely to be under estimated in favour of moderate household activities.

Employed women (table 3) had a greater number and more highly significant correlations between different categories of nonsedentary physical activity than non-employed women (table 4). This suggests that employed women were able to estimate their activities more accurately. They have more structured time during the day, and outside of working hours seem to be more aware of specific activities. Employed women therefore seemed to be better able to break down the time spent on different activities than non-employed women, who spent more time on less clearly structured moderate and heavy household activities.

The tendency to report high levels of moderate household activity on the questionnaire compared with the diary was greater for the non-employed women than employed women (differences between diary and questionnaire were 6 hours per week for non-employed women, zero for employed women). This may be a reflection of the observation above that certain types of activity seem to take longer. Nevertheless, there were no statistically significant differences within either the employed or non-employed groups between diary and questionnaire estimates of total hours of activity, and no differences between the groups. This provides some measure of confidence that the questionnaire is providing equally good estimates of total hours of non-sedentary 
activity in both employed and non-employed women.

In table 5, the agreement between the diary and the questionnaire for subjects classified into high or low levels of activity showed that the sensitivity and the specificity were both $61.5 \%$, and Cohen's kappa was 0.23 . Although these values are low, they are better than those reported previously in the literature relating to studies of women's activity.

The problems of over or under estimation were expected. There were individual differences in the ability to estimate activity depending, in part, on the attitude of the individual to certain types of activity (seen as "good", "healthy", "burdensome", etc), and in part on the inevitable over lapping between certain categories of activity. Standing and walking, for example, are involved in many other activities. The design of the questionnaire might not have been structured enough for the women whose time is less organised throughout the day to allow them to classify readily the different components of their daily physical activity.

In the present study, the low sensitivity and specificity may be explained by the use of a diary which included only four days and which, given the subject's choice of days and seasonal variations, may not have been representative of longer term activity patterns represented by the questionnaire responses. Time constraints in the present study limited the diary to four days. The level of agreement between the diary and questionnaire measures of average total non-sedentary hours per week, and the good correlations for standing, light household work, moderate leisure and total hours are likely to be minimum estimates. The relationship between the questionnaire responses and the true activity levels is therefore likely to be at least as good and probably better than the relationship between diary and questionnaire. ${ }^{30} \mathrm{~A}$ seven day diary repeated every three months for one year would, in theory, have provided a more accurate reflection of an individual's usual pattern of activity and provided a better reference measure against which to assess the validity of the questionnaire responses.

An important finding relating to all the women in the study was that the level of accuracy in reporting non-sedentary activities on the questionnaire appeared to improve with an interview. An interview allowed for corrections (in terms of both hours and categorisation of activities). The interview was also used to clarify entries in the diary, especially the leisure activities listed at the end of the diary, although it is important to note that clarification of the diary information took place after the review of the questionnaire responses and the two sets of responses were kept independent.

This questionnaire is the first of which we are aware that aims to elicit directly the number of hours per week of non-sedentary activity, rather than to create a score or index based on categorical responses. It was designed specifically to measure weight bearing and muscle pull activities which are likely to relate to bone status. It has been designed specifically for perimenopausal and early postmenopausal women (aged 45-60). The level of agreement between questionnaire and diary is better than that reported in most other validation studies, in spite of the relatively small number of subjects in the present study.

A purely postal questionnaire may always be flawed as a measure of habitual activity because subjective impressions regarding levels of intensity of different activities appear to differ between subjects and need clarification by an interviewer. In the present study, the use of a brief interview with subjects following completion of the questionnaire resulted in a substantial improvement in estimates of time spent in non-sedentary activities. It is reasonable to speculate that the combination of a questionnaire plus short diary (both of which can be posted to subjects), together with a brief interview (which can be carried out by telephone), may provide the most useful information for epidemiological studies. An alternative may be to ask subjects to maintain activity diaries over an extended period of time. The two latter approaches would need to be assessed in an epidemiological context. Until such studies are completed, it seems appropriate to recommend the questionnaire and interview described in this paper as the most effective technique reported to date for assessing habitual levels of non-sedentary physical activity.

1 National Forum for Coronary Heart Disease Prevention. Physical activity: An agenda for action. London: National Forum for Coronary Heart Disease Prevention, 1995.

2 Davey Smith G, Morris JN. Assessment of physical activity, and physical fitness, in population surveys. $\mathcal{F}$ Epidemiol Community Health 1992;46:89-91.

3 Smith EL, Raab DM. Osteoporosis and physical activity. Acta Med Scand 1986;711:149-56.

4 Smith EL, Smith PE, Ensign CJ, Shea MM. Bone involution decreases in exercising middle aged women. Calcif Tissue Int 1984;36:S129-38.

5 Heaney RP. Prevention of age-related osteoporosis in women. In Avioli LL, ed. The osteoporotic syndmome. New York: Grune and Stratton, 1983:123-44

6 Aloia JF, Cohn SH, Ostuni JA, Cane R, et al. Prevention of involutional bone loss by exercise. Ann Intern Med 1978; 89:356-58.

7 LaPorte RE, Sandler RB. Physical activity and osteoporosis. In: NIH consensus development conference report, Bethesda, $M D$. Washington DC:US GPO;56:1984;195-216.

8 Cooper C, Barker DJP, Wickham C. Physical activity, muscle strength and calcium intake in fracture of the proximal femur in Britain. $B M \mathcal{F} 1988 ; 297: 1443-46$.

9 Wickham CAC, Walsh K, Cooper C, Barker DJP, et al. Dietary calcium, physical activity and risk of hip fracture: a prospective study $B M 7$ 1989.299: 889-92.

10 Matkovic V, Kostial K, Siminovic I, Buzina R, et al. Bone status and fractures rates in two regions of Yugoslavia. Am $\mathcal{F}$ Clin Nutr 1979;32: 540-49.

11 Falch JA, Ilebekk A, Slungaard U. Epidemiology of hip fractures in Norway. Acta Orthop Scand 1985;56:12-16.

12 Serno I, Johnell O. Anderson T. Differences in the in cidence of hip fractures and some social conditions between an urban and rural population in southern Sweden. Acta Orthop Scand 1988;59:382-85.

13 Law MR, Wald NJ, Meade TW. Strategies for prevention of osteoporosis and hip fracture. BMF 1991;303:453-58.

14 Cooper C, Wickham C, Coggon D. Sedentary work in middle life and fracture of the proximal femur. $\mathrm{Br} \mathcal{F}$ Indust Med 1990;47:69-70.

15 Dalen N, Olsson KE. Bone mineral content and physical activity. Acta Orthop Scand 1974;45:170-74.

16 White MA, Martin RB, Yeater RA, Butcher RL, Radin EL The effect of exercise on the bones of postmenopausal women. Int Orthop 1984;7:209-214.

17 Krolner B, Toft B, Nielsen SP, Tondevold E. Physical exercise as prophylaxis against involutional vertebral bone loss: a controlled trial. Clin Sci 1983;64:541-546.

18 Pocock NA, Eisman JA, Yeates MG, Sambrook PN, et al. Physical fitness is a major determinant of femor, et al. Physical fitness is a major determinant of femoral neck 78:618-21.

19 LaPorte RE, Montoye HJ, Caspersen CJ. Assessment of physical activity in epidemiologic research: problems and physical activity in epidemiologic research: pro 
20 Kriska AM, Sandler RB, Cauley JA, LaPorte RE, et al. The assessment of historical physical activity and its relation to adult bone par AM. Comparison of methods to measure physical activity in postmenopausal women. Am f Clin Nutr 1987;45: 14-22.

22 Paffenbarger RS, Wing AL, Hyde TR. Physical activity as an index of heart attack risk in college alumni. Am $\mathcal{Y}$ Epidemiol 1978;108:161-65.

23 Baeke JA, Burema J, Fritjers JE. A short questionnaire for the measurement of physical activity in epidemiological studies. Am 7 Clin Nutr 1982;36:936-42.

24 Pols MA, Peeters PHM, Bueno-de-Mesquita HB, Ocke MC, Wentink CA, Kemper HCG, Collette HJA. Validity and repeatability of a modified Baeke questionnaire on physical activity. Int $\mathcal{f}$ Epidemiol 1995;24:381-88.
21 Cauley JA, LaPorte RE, Sandler RB, Schramm MM, Kriska Auley JA, LaPorte RE, Sandler RB, Schramm MM, Kriska

25 Voorrips LE, Ravelli ACJ, Dongelmans PCA, Deurenberg $P$, Van Staveren WA. A physical activity questionnaire for the elderly. Med Sci Sports Exerc 1991;23:947-79.

26 Nelson M, Mayer AB, Rutherford O, Jones D. Calcium intake, physical activity, and bone mass in premenopausal wome women.

27 Astrad PO, Rodhal K. Evaluation of physical performance on the basis of tests. Text book of physiology. 3rd ed. New York:

28 SPSSX. Statistical package for the social sciences. 3rd ed. Chicago: SPSS, 1988.

29 Gregory J, Foster K, Tyler H, Wiseman M. The dietary and nutritional survey of British adults. London: HMSO, 1990. 30 Nelson M. The validation of dietary assessment. In: Margetts BM, Nelson M. Design concepts in nutritional epidemiology. 2nd ed. Oxford: Oxford University Press, 1997.

Enter below the total hours per week in household activities:

Light Moderate Heavy

The following are questions about your activity NOW. Please answer as accurately as you can by putting a ring around the answers that apply best to you, or by entering the time spent in each activity.

- 1. Do you go out to work (full or part time)? Yes No

If No, go to question 2 below.

If Yes, what is you occupation?

a) Please state the type of industry or institution, give your job title, and describe the type of work you do.

b) How many HOURS PER WEEK do you work (including time spent in lunch and tea breaks)? hours per week

c) At work, roughly how many HOURS PER WEEK do you spend:

$\begin{array}{ll}\text { Sitting } & \text { Walking _ } \\ \text { Standing } & \text { Other } \\ \text { specify } \_ \text {(Please }\end{array}$

Include time spent in lunch and tea breaks and exclude time spent on the journey to and from work. Please make sure that the total hours of activity add up to the total number of hours worked.

d) On your way TO AND FROM work (the round trip), how long do you spend per week:

Sitting minutes per week

Standing minutes per week

Walking minutes per week

Cycling minutes per week

\section{HOUSEHOLD ACTIVITIES}

- 2. Roughly how many HOURS PER WEEK do you usually spend in the following household activities?

\begin{tabular}{|c|c|c|}
\hline Light & Moderate & Heary \\
\hline Cooking & Cleaning (including windows) & Scrubbing the floor \\
\hline Washing up & Vacuum cleaning & Beating mats \\
\hline Setting the table & Sweeping & Walking with heavy shopping \\
\hline Clearing up after meals & Washing floor & $\begin{array}{l}\text { Other heavy household } \\
\text { activities (specify): }\end{array}$ \\
\hline Washing clothes (machine) & Washing clothes (by hand) & \\
\hline Tidying the house & Making beds & \\
\hline Dusting & $\begin{array}{l}\text { Shopping for food or other } \\
\text { household items }\end{array}$ & \\
\hline $\begin{array}{l}\text { Other light household } \\
\text { activities (specify): }\end{array}$ & $\begin{array}{l}\text { Other moderate household } \\
\text { activities (specify): }\end{array}$ & \\
\hline
\end{tabular}

\section{LEISURE TIME ACTIVITIES}

Think about how many times you go out during the week (including weekends) - activities such as taking children to school, walking the dog, visiting friends, shopping trips, etc. Exclude the journey to work, any other trips already mentioned, and waling or cycling for pleasure.

- 3. How long do you spend walking in an average week? hours per week

- 4. How long do you spend cycling in an average week? hours per week

- 5. Listed below are a variety of sport, leisure, and domestic activities. For each activity which you do, write down in the table below:

- The name of the activity;

- How much time you spend (on average) each item you do the activity;

- How many times per month you do the activity;

- How many months in the year you do the activity.

(For example, you might play tennis for one hour, four times per month, for three months in the year. If there are any other sports or activities you do regularly which are not listed, please enter them in the table.)

\begin{tabular}{llll}
\hline Activity & $\begin{array}{l}\text { Time (h) per } \\
\text { occasion }\end{array}$ & $\begin{array}{l}\text { Times } \\
\text { per month }\end{array}$ & $\begin{array}{l}\text { Months } \\
\text { per year }\end{array}$ \\
\hline
\end{tabular}


Light activities: preparation time for sports, fishing

Moderate activities: Gardening (other than digging), home decorating, calisthenics, horse riding/grooming, walking for pleasure (flat), cycling for pleasure (flat), sailing.

Hard activities: weight training, circuit training, tennis, badminton, walking for pleasure (hilly), cycling for pleasure (hilly), aerobics/ dancing, jogging.

Very hard activities: digging, swimming/skin diving, squash, skiing, running.

\section{Appendix II}

\section{Physical activity diary}

- 1. Please write down the details of your activities for any two week days and two weekend days (a total of four days). If you work full time, and your days off occur during the week, consider these days as weekend days.

- 2. Main activity. For each time interval shown, write down the type of activity using the following letters. You can add other activities not listed.

\section{L lying \\ T standing \\ C cycling \\ $\mathrm{G}$ gardening \\ $M$ swimmin \\ $\mathrm{R}$ carrying object or children \\ $\mathrm{J}$ jogging}

E exercising
D driving W driving

- 3. Description. For each letter, give a brief description of the activity (see example). Note

that some activities may be light, moderate, or heavy. Gardening, for example, can be light (standing watering the lawn), moderate (planting). Or heavy (digging). Walking and cycling may be level or hilly, slow, average, or vigorous.

- 4. You may list two or more types of activity in one time interval. In the example below, " $T$ " and " $W$ " were listed in the interval 9.30-10.00, described as "climbing stairs, tidying up, getting dressed".

\begin{tabular}{lll}
$\begin{array}{l}\text { Activity diary } \\
\text { Day: Sunday }\end{array}$ & $\begin{array}{c}\text { Tymple } \\
\text { Type of day: weekend }\end{array}$ \\
\hline Time & Main activity & Description \\
\hline $5.00-5.30$ & $L$ & $\begin{array}{l}\text { Asleep } \\
\text { Asleep }\end{array}$ \\
$6.30-6.00$ & $L$ & Asleep \\
$6.00-6.30$ & $L$ & Asleep \\
$7.00-7.00$ & $L$ & Washing \\
$7.30-8.00$ & $T$ & Preparing and eating breakfast \\
$8.00-8.30$ & $S, S$ & Eating breakfast \\
$8.30-9.00$ & $S$ & Reading a newspaper \\
$9.00-9.30$ & $S$ & Climbing sewspaper \\
$9.30-10.00$ & $T, W$ & getting dressed tidying up, \\
& Walking to the shops \\
$10.00-10.30$ & $W$ & Walking to the shops \\
$10.30-11.00$ & $W$ & Shopping \\
$11.00-11.30$ & $T, W$ & Shopping \\
$11.30-12.00$ & $T, W$ & Eating lunch \\
$12.00-12.30$ & $S$ & Eating lunch \\
$12.30-13.00$ & $S$ & Walking home, carrying the \\
$13.00-13.30$ & $W, R$ & shopping \\
& Lying down \\
$13.30-14.00$ & $L$ & Lying down \\
$14.00-14.30$ & $L$ & Mowing the lawn \\
$14.30-15.00$ & $G$ &
\end{tabular}

